\title{
Osteoarthritis research priorities: a report from a EULAR ad hoc expert committee
}

\author{
Philip G Conaghan, ${ }^{1}$ Margreet Kloppenburg, ${ }^{2}$ Georg Schett, ${ }^{3}$ Johannes W J Bijlsma, ${ }^{4}$ \\ on behalf of a EULAR osteoarthritis ad hoc committee
}

\begin{abstract}
Handling editor Tore K Kvien
${ }^{1}$ Leeds Institute of Rheumatic and Musculoskeletal Medicine, University of Leeds and NIHR Leeds Musculoskeletal Biomedical Research Unit, Leeds, UK

${ }^{2}$ Department of Rheumatology, Leiden University Medical Center, Leiden, The Netherlands

${ }^{3}$ Department of Internal Medicine 3, Rheumatology and Immunology, University of Erlangen-Nuremberg, Erlangen, Germany

${ }^{4}$ Department of Rheumatology \& Clinical Immunology, University Medical Center Utrecht, Utrecht, The Netherlands
\end{abstract}

Received 24 September 2013 Revised 6 February 2014 Accepted 1 March 2014 Published Online First 13 March 2014

\section{ABSTRACT}

Osteoarthritis (OA) currently affects over 40 million Europeans, with its associated personal suffering and significant economic burden for health systems set to dramatically escalate in a rapidly ageing Europe. Given the very limited effective therapeutic options for OA, the European League Against Rheumatism (EULAR) created an ad hoc committee of OA researchers, clinicians and patients to consider a research agenda focussed on the areas of epidemiology, pathogenesis, imaging and biomarkers, and therapies. The committee deliberated and listed research needs in these areas and also established some cross-area priority themes: predictors of OA progression, especially where this might enable stratified interventions; understanding mechanisms of $\mathrm{OA}$ pain; improved understanding of tissue communication in a process where multiple tissue pathologies are common; developing concepts of, and consequently interventions for, early OA where both pain and structural processes may be more effectively targeted than in typical clinical presentations; and the need for new treatment strategies, with examples discussed on pathology-targeted therapies and optimal combinations of therapies. This research agenda should provide useful guidance for all researchers in this field and hopefully lead to improved OA care.

\section{THE GROWING BURDEN OF OSTEOARTHRITIS}

Musculoskeletal diseases are now the second greatest cause of disability in all regions of the world, with osteoarthritis (OA) showing the greatest increase in the last 20 years. ${ }^{12}$ OA currently affects at least 40 million people in Europe ${ }^{3-10}$ and accounts for more than a third of chronic moderate to severe pain. ${ }^{11}$ It is strongly age-related, prompting further concerns as population projections suggest that by 2025 there will be over 210 million people over 65 in Europe. ${ }^{12-14}$ Quality-of-life studies suggest that the impact of OA is comparable to that of cardiac, neurological and pulmonary diseases in terms of effect on daily functioning and health-related quality of life. ${ }^{8}$

The cost of OA in Europe is currently estimated at $0.5 \%$ of gross national product, reflecting the cumulative cost of absence from work, medical costs and community and social services. ${ }^{15-20}$ In a 2003 French macroeconomic study, which included an estimated 3-4.6 million people with OA, the direct costs of OA exceeded $€ 1.6$ billion, similar to that spent on coronary heart disease. Compared with a similar study conducted 10 years earlier, the population of patients with $\mathrm{OA}$ in France had increased by $54 \%$. Physician visits increased by a similar proportion, with 13 million visits attributed to $\mathrm{OA}$ in a 3 -year period, resulting in 18 million prescriptions at a cost of $€ 570$ million, a $400 \%$ increase compared with $1993 .^{20}$ Indirect costs related to OA are also high, with an estimated $£ 3.2$ billion in lost production in the UK attributed to $\mathrm{OA}$ in $1999-2000,{ }^{19}$ while in France 5 million sick-leave days are prescribed for OA each year, costing $€ 180$ million in sick-leave benefits. ${ }^{20}$ In a prospective Swedish study, musculoskeletal disease (most notably OA) was the most expensive disease category, representing $22.6 \%$ of the total cost of illness; the greatest costs were indirect costs related to morbidity and disability. ${ }^{16}$

For severe symptoms, joint replacement may be the only option, and this is also rapidly increasing. $^{20-22}$ In 2011, 165000 total hip and knee replacements were performed in the UK, 93\% of which were for OA. ${ }^{21}$ Similar figures were observed in France, where 118000 primary joint arthroplasties were performed, ${ }^{20}$ and Sweden, where hip arthroplasty is reported to occur at a frequency of 332 in every 100000 people aged over 40, an increase of $41 \%$ in 10 years. ${ }^{22}$ Demand is predicted to soon exceed orthopaedic capacity.

In light of the above, the European League Against Rheumatism (EULAR) Executive created an ad hoc expert panel comprising a range of basic, translational and clinical researchers and patient involvement. This committee was charged with setting priorities for OA research, in particular by focusing on the following four areas: epidemiology, pathogenesis, imaging and biomarkers, and therapy.

\section{UNMET NEEDS IN OA RESEARCH}

The committee had a 1-day meeting and initially discussed the perceived barriers to the lack of success in improving therapies, both symptom and structure-modifying. Some of the areas highlighted were: the historic focus on inflammatory arthritis by the relevant musculoskeletal research community; a cartilage-centric approach to a process that involves multiple tissue pathologies; lack of engagement of primary care and little cross-specialty communication; waning industry investment; and a lack of focus on pain-the most important issue for people with OA.

It was felt that some of these areas had started being addressed to some extent in the last few years, identifiable in both EULAR initiatives in collaboration with orthopaedics and primary care and in recent trends in OA science and treatments. ${ }^{23}$ However, considerable unmet needs remained, including a limited understanding of phenotypes allowing targeted interventions and a lack of conceptual definitions and concepts of what might 
constitute 'early' OA. The group felt that there was an important role for EULAR to continue promoting European collaboration (between both researchers and industry and across primary care and specialties). It was felt we should also learn from successful approaches in other chronic diseases.

With the unmet needs in mind, important research topics according to the four areas within the remit of this committee were then discussed and prioritised in break-out groups.

\section{RESEARCH PRIORITY AREAS}

\section{Epidemiology}

The natural history of OA is still largely unknown. Two topics especially warrant attention.

- The progressive OA disease course in some patients

The disease course of OA is heterogeneous, with some experiencing rapidly increasing pain, disability or structural damage in a relatively short timeframe, while others have stable disease over many years. ${ }^{24}$ The underlying mechanisms and risk factors for progression are still largely unknown. However, the prediction of progression is of interest, from both the patient (prognosis) and research perspective. Identification of progressors will enable phenotyping of $\mathrm{OA}$ and preferential inclusion of these progressor phenotypes in clinical trials, which may help to prevent too many negative clinical trials, as have been observed previously. In addition, this may enable the development of a clinical decision tool to predict progression, such as the FRAX, which is used in osteoporosis.

- The early phases in OA development

It could be argued that patients with radiological damage are already in an end stage of the disease. From a patient and research perspective, treatment at an earlier stage, when prevention of radiological damage is still achievable, is much more attractive. To enable the development of treatments and the performance of clinical trials in the early phases of OA, criteria that define early or pre-OA are essential. ${ }^{25}$

Additional topics on the research agenda include the following.

- Criteria to diagnose and classify generalised or multisite OA

The definition of generalised or total body OA could facilitate research in biomarkers and stratification of patients in clinical trials. $^{26}$

- The multidimensionality of OA outcomes

Pain is central in the disease process; however, it is important to also study the relevance of other domains, including function, participation and performance, and to incorporate these domains into outcome assessment in OA.

- Foot OA

This is a common presentation of OA that is seldom studied, but with a potentially high clinical burden. ${ }^{27}$ Studies should be performed to elucidate its prevalence and clinical impact, including its role in functional impairment.

\section{Pathogenesis}

The pathophysiology of OA is not fully understood and has been dominated by research on the mechanisms of cartilage breakdown and chondrocyte biology. There is a need to develop the concept of OA as a disease of an entire organ, suggesting that it may not be sufficient to understand OA by focusing only on intrinsic changes in the cartilage metabolism. Novel aspects of the pathophysiology of OA have attracted attention, and these frontiers to explore include the following.

- Better understanding of tissue communication in OA

The interactions between cartilage and the adjacent bone, as well as between the synovium and adipose tissue, have not been well explored. Studying this relationship offers opportunities for novel interventions. ${ }^{28}$

- Better understanding of non-cartilage articular pathology

Research would include characterising inflammation of the synovial membrane and the nature of subchondral bone pathology, both abnormalities that are often observed in OA. ${ }^{29}$

- Defining the mechanisms by which comorbidities influence the OA process

There have been limited studies on how common comorbid conditions such as obesity and diabetes affect OA, especially how fat and glucose metabolism may contribute to the initiation and progression of the disease. ${ }^{30}$

- Understanding joint trauma and subsequent repair

Such research would include studying the induction of developmental processes such as chondrocyte hypertrophy in OA. ${ }^{31}$ The molecular mechanisms of mechanical joint injury and their translation to inflammation and repair are still poorly defined, but of seminal importance.

- Understanding the pathology of the earliest stages of OA

This area might be addressed by studying the molecular changes following mechanical injury to the joint. ${ }^{32}$ Notably, it is still unclear what we consider as 'early OA' and which mechanisms determine whether patients either progress to the full clinical manifestation of OA or have episodic arthralgia.

- Understanding the relationship between pain and structure Of particular issue is how pain modifies the disease course of $\mathrm{OA}$ and how it relates to disease-specific mechanisms. ${ }^{33}$

\section{Imaging and biomarkers}

Robust biomarkers are required for both improving clinical trial outcomes and stratifying interventions. Areas requiring particular focus are as follows.

- Defining the performance metrics of imaging and other biomarkers

Imaging has traditionally focused on radiographic outcomes for knee OA. Less is known about the performance metrics of radiographs at other anatomical sites, or for the newer imaging modalities such as MRI and ultrasound, although the information accumulated from MRI studies in the last decade has dramatically improved our understanding of the complexity of OA pathology. ${ }^{34}$ The field of OA molecular biomarkers is extensive, and challenges have included establishing the technical validity of candidate biomarkers, having feasible collection of biosamples in trials, and understanding the relationship of such biomarkers to single-joint pathology when multiple joints may be affected in an individual. ${ }^{35}$ For both imaging and molecular biomarkers, the technical aspects, validity (including predictive validity), reliability and responsiveness require detailed attention.

- The relevance of biomarkers to a broad range of domains

When examining the importance of biomarkers, not only symptoms and structure should be considered but also other domains including broader constructs such as quality of life.

- Defining predictors of progression, especially those that aid targeted intervention

Little has been done on combining modern imaging with biomechanical variables or non-imaging biomarkers. Consideration should be given to using combinations of structural and molecular biomarkers, ${ }^{35}$ especially in stratification for intervention.

\section{Therapy}

Existing symptomatic treatment of OA often has poor analgesic effect size and is unsatisfactory for many people with OA. ${ }^{23}$ Current pharmacological therapies also have significant toxicities that limit their widespread usage. Recent EULAR guidelines 
have emphasised the importance, efficacy and safety of nonpharmacological interventions and also provided specific research recommendations. ${ }^{36}$ Structure modification has remained difficult to achieve. Areas requiring further research are as follows.

- Mechanisms of OA pain

Pain mechanisms are not well understood; pain treatment needs to be more targeted to these mechanisms, therefore investigation of the origin of pain in $\mathrm{OA}$ and its interrelation with other aspects of the disease is required. ${ }^{33}$ A potential benefit gained from studies in this area should be the identification of novel targets for pain management.

- Individualised or pathology-targeted therapies

Knowledge of phenotypes of OA can be used to target specific OA therapies-for example, if increased bone turnover was driving disease progression in a subset of patients, treatment aimed at this increased bone turnover (eg, bisphosphonates) should be evaluated, whereas, in other patients in whom disease progression is driven by synovial inflammation, treatment aimed at this inflammation (eg, methotrexate) should be evaluated. ${ }^{23}$ Studies must be performed that consider specific characteristics of patients; such knowledge of phenotypes would be useful for non-pharmacological as well as pharmacological therapies. Possible efficacious interventions may have been discarded because they were not effective in large unselected groups of patients. Therapies may also consider targeting specific related comorbidities such as obesity.

- Optimal combination therapy strategies

Most OA therapeutic studies have focused on assessing individual therapies. Identification of optimal strategies that employ combinations of available therapies would be valuable to see if greater analgesic benefit could be obtained. Such studies might include complex intervention designs and compare different therapeutic options, such as monotherapy versus combination therapy, or investigate combinations of therapies (eg, combination pharmacological or combination non-pharmacological or all combined).

\section{SUMMARY OF PRIORITIES}

Finally, after the formulation of research priorities within the above four areas, a series of consensus rounds were conducted with the entire committee. From this process the following broad priority themes were established:

- Predictors of progression of OA

- Mechanisms of pain in OA

- Treatment strategies in OA

- Early OA

- Tissue communication in OA

\section{CONCLUSIONS}

This process of bringing together European OA researchers for strategic prioritisation represents an important step for the field of OA. It is hoped this document provides useful guidance for OA researchers and at least a discussion point for national societies with interests in the field of OA. It is of course important that such strategy setting should never exclude novel thoughts or ideas that may move our understanding or treatment of OA forward.

Acknowledgements The authors wish to thank the EULAR Executive for convening this committee and to acknowledge the other members of the ad hoc committee: Daniel Aletaha, Nigel Arden, Francis Berenbaum, Wim van den Berg, Mats Brittberg, Francesco Dell'Accio, Maxime Dougados, Dick Heinegard, Tore Kvien, Floris Lafeber, Rik Lories, Frank Luyten, lain Mclnnes, Thomas Pap, Timothy Spector, Emil Thoroddsen, Thea Vliet Vlieland, Weiya Zhang.
Contributors All authors contributed to the content and drafting of the manuscript.

Competing interests None.

Provenance and peer review Not commissioned; internally peer reviewed.

\section{REFERENCES}

1 Vos T, Flaxman AD, Naghavi M, et al. Years lived with disability (YLDs) for 1160 sequelae of 289 diseases and injuries 1990-2010: a systematic analysis for the Global Burden of Disease Study 2010. Lancet 2012;380:2163-96.

2 Murray CJ, Vos T, Lozano R, et al. Disability-adjusted life years (DALYs) for 291 diseases and injuries in 21 regions, 1990-2010: a systematic analysis for the Global Burden of Disease Study 2010. Lancet 2012;380:2197-223.

3 Levy E, Ferme A, Perocheau D, et al. Socioeconomic costs of osteoarthritis in France. Rev Rhum Ed Fr 1993;60(6 Pt 2):63S-7S.

4 Watson M. Management of patients with osteoarthritis. Pharm J 1997;259:296-7.

5 Davidsen M, Kjoller M, Helweg-Larsen K. The Danish National Cohort Study (DANCOS). Scand J Public Health 2011;39(7 Suppl):131-5.

6 van Saase JL, van Romunde LK, Cats A, et al. Epidemiology of osteoarthritis: Zoetermeer survey. Comparison of radiological osteoarthritis in a Dutch population with that in 10 other populations. Ann Rheum Dis 1989;48:271-80.

7 Symmons D, Mathers C, Pfleger B. Global burden of osteoarthritis in the year 2000. Report on the Global Burden of Disease, 2000.

8 Loza E, Abasolo L, Jover JA, et al. Burden of disease across chronic diseases: a health survey that measured prevalence, function, and quality of life. J Rheumatol 2008;35:159-65.

9 Danielsson L, Lindberg H. Prevalence of coxarthrosis in an urban population during four decades. Clin Orthop Relat Res 1997;342:106-10.

10 Vavken P, Dorotka R. Burden of musculoskeletal disease and its determination by urbanicity, socioeconomic status, age, and sex: Results from 14,507 subjects. Arthritis Care Res 2011;63:1558-64.

11 Breivik H, Collett B, Ventafridda V, et al. Survey of chronic pain in Europe: prevalence, impact on daily life, and treatment. Eur J Pain 2006;10:287-333.

12 National population projections, 2008-based. Office for National Statistics, UK. 2009.

13 The bone and joint decade 2000-2010 for prevention and treatment of musculo-skeletal disorders. Lund, Sweden, April 17-18, 1998. Proceedings. Acta Orthop Scand Suppl 1998;281:1-86.

14 Heilig G. The European Rural Development project http://wwwiiasaacat/Research/ ERD/indexhtml. 2002.

15 Loza E, Lopez-Gomez JM, Abasolo L, et al. Economic burden of knee and hip osteoarthritis in Spain. Arthritis Rheum 2009;61:158-65.

16 Jacobson L, Lindgren B. What are the costs of illness? Stockholm: Socialstyrelsen (National Board of Health and Welfare). 1996.

17 Leardini G, Salaffi F, Caporali R, et al. Direct and indirect costs of osteoarthritis of the knee. Clin Exp Rheumatol 2004;22:699-706.

18 Rabenda V, Manette $C$, Lemmens $R$, et al. Direct and indirect costs attributable to osteoarthritis in active subjects. J Rheumatol 2006;33:1152-8.

19 Department for Work and Pensions. Analytical Services Division. http://www.dwp. gov.uk

20 Le Pen C, Reygrobellet C, Gerentes I. Financial cost of osteoarthritis in France. The "COART" France study. Joint Bone Spine 2005;72:567-70.

21 National Joint Registry. 2009.

22 Garrellick G, Karrholm J, Rogmark C, et al. Swedish Hip Arthroplasty Register. Annual Report 2011

23 Bijlsma JW, Berenbaum F, Lafeber FP. Osteoarthritis: an update with relevance for clinical practice. Lancet 2011;377:2115-26.

24 Chapple CM, Nicholson H, Baxter GD, et al. Patient characteristics that predict progression of knee osteoarthritis: a systematic review of prognostic studies. Arthritis Res Ther 2011;63:1115-25.

25 Wesseling J, Dekker J, van den Berg WB, et al. CHECK (Cohort Hip and Cohort Knee): similarities and differences with the Osteoarthritis Initiative. Ann Rheum Dis 2009;68:1413-19.

26 Nelson AE, Smith MW, Golightly YM, et al. 'Generalized osteoarthritis': a systematic review. Semin Arthritis Rheum 2013. [Epub ahead of print 31 Dec 2013]. doi: 10.1016/j.semarthrit.2013.12.007

27 Roddy E, Thomas MJ, Marshall M, et al. The population prevalence of symptomatic radiographic foot osteoarthritis in community-dwelling older adults: cross-sectional findings from the Clinical Assessment Study of the Foot. Ann Rheum Dis 2013. Published Online First 19 Nov 2013. doi: 10.1136/annrheumdis-2013-203804

28 Karsdal MA, Bay-Jensen AC, Lories RJ, et al. The coupling of bone and cartilage turnover in osteoarthritis: opportunities for bone antiresorptives and anabolics as potential treatments? Ann Rheum Dis 2014;73:336-48.

29 Wenham CY, Conaghan PG. Imaging the painful osteoarthritic knee joint: what have we learned? Nat Clin Pract Rheumatol 2009;5:149-58.

30 Sellam J, Berenbaum F. Is osteoarthritis a metabolic disease? Joint Bone Spine 2013;80:568-73. 
31 van der Kraan PM, van den Berg WB. Chondrocyte hypertrophy and osteoarthritis: role in initiation and progression of cartilage degeneration? Osteoarthritis Cartilage 2012;20:223-32.

32 Chu $\mathrm{CR}$, Williams AA, Coyle $\mathrm{CH}$, et al. Early diagnosis to enable early treatment of pre-osteoarthritis. Arthritis Res Ther 2012:14:212

33 Lee $A S$, Ellman MB, Yan $D$, et al. A current review of molecular mechanisms regarding osteoarthritis and pain. Gene 2013;527:440-7.
34 Guermazi A, Hayashi D, Roemer FW, et al. Osteoarthritis: a review of the strengths and weaknesses of different imaging options. Rheum Dis Clin North Am 2013;39:567-91.

35 Lotz M, Martel-Pelletier J, Christiansen C, et al. Value of biomarkers in osteoarthritis: current status and perspectives. Ann Rheum Dis 2013;72:1756-63.

36 Fernandes L, Hagen KB, Bijlsma JWJ, et al. EULAR recommendations for the non-pharmacological core management of hip and knee osteoarthritis. Ann Rheum Dis 2013:72:1125-35. 


\section{Osteoarthritis research priorities: a report from a EULAR ad hoc expert committee}

Philip G Conaghan, Margreet Kloppenburg, Georg Schett, Johannes W J Bijlsma and on behalf of a EULAR osteoarthritis ad hoc committee

Ann Rheum Dis 2014 73: 1442-1445 originally published online March 13, 2014

doi: 10.1136/annrheumdis-2013-204660

Updated information and services can be found at:

http://ard.bmj.com/content/73/8/1442

\section{These include:}

References This article cites 26 articles, 8 of which you can access for free at: http://ard.bmj.com/content/73/8/1442\#BIBL

Email alerting Receive free email alerts when new articles cite this article. Sign up in the service box at the top right corner of the online article.

\section{Notes}

To request permissions go to:

http://group.bmj.com/group/rights-licensing/permissions

To order reprints go to:

http://journals.bmj.com/cgi/reprintform

To subscribe to BMJ go to:

http://group.bmj.com/subscribe/ 